\title{
An Analysis of Non-exchangeable Values of Rural Environments
}

\author{
— Based on Attitudes towards Indonesian Sightseeing Resources
}

\author{
Shinobu Kitani*, Tadashi Hasebe*, Noriaki Nomura** \\ and Richard MoORE***
}

\begin{abstract}
The value of Indonesian sightseeing is analyzed from various different viewpoints. Conjoint Analysis and the Analytic Hierarchy Process (AHP) are used as basic tools for evaluation, where Indonesian sightseeing is divided into three travel type components: nature travel, traditional history travel, and agricultural area travel. The values calculated by ranking-type conjoint models are utilities of each travel plan which are also compared to the utilities of traveling expenses. Surveys were carried out in five countries: Japan, the United States, Netherlands, Singapore, and Indonesia. Using a personal computer, respondents first ranked nine tour plans, which were composed of three travel types as previously mentioned. After that, the respondents compared a set of photographs related to travel types for processing AHP, and they ranked the tour plans again. Nature travel appeared to be the most attractive overall, and agricultural area travel had a negative value except for the Dutch and Indonesian cases. Influences of AHP investigation revealed substantial differences between the five surveys. Agricultural area travel became more attractive after the AHP exercise for Japanese, Singaporeans, and Dutch respondents taken together. Dutch and Indonesians made an interesting change of attitudes after the AHP exercise. This fact was interpreted using the Elaboration Likelihood Model for attitudinal change in social psychology.
\end{abstract}

JEL Classification: Q51

Keywords: Conjoint Analysis, Analytic Hierarchy Process, Non-exchangeable Value, Rural Environments, Attitudinal Change

\section{Introduction}

This article shows the results of surveys of young students in several countries regarding their preferences on sightseeing in Indonesia and discusses the value of travel in Indonesia, where we pay attention to respondents' attitudinal changes during the process of revealing their preferences. In the usual analytical framework, values on economic goods are considered as utilities through consuming them, even if these goods are public such as the case of

* Graduate School of Agricultural Science, Tohoku University, 1-1 Tsutsumidori-Amamiyamachi, Aoba-ku, Sendai, 981-8555, Japan e-mail : skitani@mail.tains.tohoku.ac.jp

** Graduate School of Engineering, Tohoku University

*** Ohio Agricultural Research and Development Center, Ohio State University

Received : 31 December 2006 Accepted : 15 October 2007

(C) 日本地域学会（JSRSAI） 2007 
environmental goods. We call them "exchangeable value". Well then, how can we grasp non-exchangeable value of environmental goods? Some moral philosophers assert that everything has an intrinsic value in view of biocentrism while others say that the importance of environmental goods may be more strongly derived from its symbolic meaning ${ }^{1)}$.

Because ideas of non-exchangeable value by these philosophers are not demonstrated in econometric frameworks, it has been hard to incorporate their assertions into environmental evaluations that are mainly researched in market mechanisms. Related to non-exchangeable value, we have carried out another survey to measure the value of agricultural landscape a few years ago, and to find a relationship between a decision process of respondent's preference and his/her accessibility to a farm village during childhood [6]. On the issue of rural farming from ethical points of view, Thompson took up the topic of the value of family farming [11] and Mepham asked how we could manage the influence of agribusiness on rural agriculture [7]. Further, Shrader-Frechette called for the government to protect family farms $[10]$. We consider that the values concerning "rural" or "family" might be embedded in non-exchangeable value.

In this article, we try to present some ground for the existence of non-exchangeable values concerning Indonesian rural environments by investigating respondents' attitudinal changes revealed by their change in preferences regarding Indonesian sightseeing. Surveys were carried out in Japan and other countries from 2000 to 2002, conducted by the agro-ethics study group in Tohoku University.

First, we developed a Japanese version of the survey in the 2000 fiscal year for the purpose of measuring the economic value of sightseeing in Indonesia based on attractions in various tour plans. The survey system was designed for use on a personal computer to collect preference data on various tour plans in Indonesia (called PC survey system in short). The data were analyzed using the conjoint model of ranking type. The model is briefly shown in the following section. From the viewpoint of the Indonesian tourist industry, it is clearly important to grasp the Indonesian tourist attractions from a world-wide viewpoint. Moreover, because we originally laid out the purpose of the survey on evaluating agroenvironments comprehensively and globally, overseas investigation became necessary. As a result, the survey was translated into English in the 2001 fiscal year and additional surveys were carried out in the United States, Netherlands, and Singapore.

There is another point to be checked concerning the survey. If there were any differences of personal preferences between Indonesia and other countries, it would seem to be difficult to develop the sightseeing resources of Indonesia. Therefore, we also carried out the survey in Indonesia, where the survey was modified to accommodate local preferences for shorter tour plans and briefer explanations about Indonesian environmental resources and history. In this article we shall refer to the conjoint model to measure the strength of preference (i.e., utility) of three types of travel, and explain how to evaluate Indonesian

\footnotetext{
1) For example, according to Callicott, every thing equally has an intrinsic or inherent value in view of biocentrism [1], and Heller says "An important element of the demand for preservation may be derived less from its instrumental utility than from its symbolic meaning." [3] Or, Sagoff says, "it is fair to say that the worth of the things we love is better measured by our unwillingness to pay for them" (p. 68) [9].
} 
sightseeing. Next, the content of the survey and the results of a comparative analysis of the five surveys are shown. Last, we shall discuss the degree of vulnerability to preference change over time.

\section{Conjoint Model (Ranking Type) and Contents of Survey}

\subsection{Description of the model}

The model can be described mathematically as follows.

Let $x_{j i}$ be the level of the $j$-th attribute of the $i$-th profile $(i=1,2, \cdots, I ; j=1,2, \cdots, J)$. Then, the utility level (random variable) $u_{i}$ of the $i$-th profile may be expressed as :

$$
u_{i}=f\left(x_{1 i}, x_{2 i}, \cdots, x_{J i}\right)+\varepsilon_{i}
$$

where each of $\varepsilon_{i}$ is an random variable error such that $E\left(\varepsilon_{i}\right)=0$ and has a Gumbel distribution independent of each other, and $f$ is a structure function showing what form the level of $J$ attributes have determined the utility.

The respondent $k$ has a preference relation $>_{k}$ (a linear binary relation) on the set of profiles, and let the relation be:

$$
i(1)_{k}>_{k} i(2)_{k}>_{k} \cdots>_{k} i(I)_{k}
$$

$S_{k}\left(i^{*}\right)$ is a set of profiles of $k$ which is located below the $i^{*}$-th profile, and $P_{k}(i, S)$ is a probability that $k$ chooses $i$ from a set of profiles $S$. That is:

$$
S_{k}\left(i^{*}\right)=\left\{i \mid i\left(i^{*}\right)_{k}>_{k} i\right\}, \quad P_{k}(i, S)=P\left\{u_{i}>_{k} u_{j}(\forall j \in S)\right\}
$$

Then, the likelihood $L$ can be expressed by:

$$
L=\prod_{k}\left\{\prod_{i^{*}=1}^{I-1} P_{k}\left(i^{*}, S_{k}\left(i^{*}\right)\right)\right\}
$$

Parameters of structure function $f$ can be decided to maximize $L$. Here, we assume that $f$ is linear;

$$
f\left(x_{1 i}, x_{2 i}, \cdots, x_{J i}\right)=\alpha+\beta_{1} x_{1 i}+\beta_{2} x_{2 i}+\cdots+\beta_{J} x_{J i}
$$

and we come to seek the vector of parameters $\left(\alpha, \beta_{1}, \beta_{2}, \cdots, \beta_{J}\right)$ to maximize $L$.

Further, because an error of observation is supposed to have a Gumbel distribution, $P_{k}(i$, S) can be expressed by :

$$
P_{k}(i, S)=\frac{\exp \left(f_{i}\right)}{\sum_{i \in S} \exp \left(f_{i}\right)}\left(f_{i}=f\left(x_{1 i}, x_{2 i}, \cdots, x_{J i}\right)\right)
$$

\subsection{Contents of the survey}

To evaluate Indonesian sightseeing resources, we focused on two aspects : a value based on tourist preferences and a configuration of tourist attractions. The former can be calculated by expressed rankings using the conjoint model described above. For the latter aspect, we asked respondents to compare criteria related to three travel types based on their relative attraction, and apply AHP (the Analytic Hierarchy Process) to grasp a configuration of their preferences. The survey is composed of two parts as follows :

(1) expressing rankings on nine tour plans for our conjoint analysis.

(2) expressing strength of attractions through repetitive pair-wise comparisons of 
Table 1. Orthogonal arrangement for tour plans*

\begin{tabular}{|c|c|c|c|c|c|c|}
\hline \multirow{2}{*}{$\begin{array}{c}\text { Tour } \\
\text { plans }\end{array}$} & \multicolumn{4}{|c|}{ Travel } & \multicolumn{3}{c|}{ Traveling Expenses } \\
\cline { 2 - 7 } & Nature & $\begin{array}{c}\text { Traditional } \\
\text { History }\end{array}$ & Agriculture & Japan $¥$ & $\begin{array}{c}\text { U.S. } \$ \text {, Euro } \\
\text { Singapore } \$\end{array}$ & Indonesia Rp. \\
\hline C1 & 2 days & 2 days & 2 days & 50,000 & 500 & 200,000 \\
\hline C2 & 4 days & 4 days & 4 days & 50,000 & 500 & 200,000 \\
\hline C3 & 6 days & 6 days & 6 days & 50,000 & 500 & 200,000 \\
\hline C4 & 6 days & 4 days & 2 days & 75,000 & 750 & 300,000 \\
\hline C5 & 2 days & 6 days & 4 days & 75,000 & 750 & 300,000 \\
\hline C6 & 4 days & 2 days & 6 days & 75,000 & 750 & 300,000 \\
\hline C7 & 4 days & 6 days & 2 days & 100,000 & 1,000 & 400,000 \\
\hline C8 & 6 days & 2 days & 4 days & 100,000 & 1,000 & 400,000 \\
\hline C9 & 2 days & 4 days & 6 days & 100,000 & 1,000 & 400,000 \\
\hline
\end{tabular}

* In the Indonesian survey, the amount of travel (the number of days) is all cut in half because Indonesians usually travel domestically less 10 days. Traveling expenses in Indonesia were settled by consulting an Indonesian researcher about the consumer price, not by referring to the exchange rate.

AHP criteria.

One of the purposes of our research is to find whether repeated pair-wise comparisons of pictures for (2) above might give respondents any stimulation about a tourist attraction to Indonesia, so we conducted (1) again after the initial AHP investigation (2).

In the survey, sightseeing in Indonesia includes the following three types of plans : first, nature travel plan; second, a traditional history travel plan; and last, an agricultural area travel plan. In the nature travel plan, playing on the beach, hiking in the mountains and valleys, and seeing native animals are all part of the natural wonders to enjoy. In the traditional history travel plan, traveling to historic sights will allow to enjoy the cultural history of Indonesia through visiting temples and ruins, watching traditional plays, or participating in festivals. In the agricultural area travel plan, through visiting agricultural areas, farm life, the countryside and Indonesian farming can be experienced. Throughout the survey, the Indonesian Government assists all respondents with travel expenses to Indonesia supposed the latter design a travel plan in Indonesia using their own money.

According to the conjoint model as indicated above, a set of profiles consists of tour plans which have four attributes (three types of travel plans and traveling expenses inside Indonesia) each having three levels (Table 1). Theoretically, there may be $81\left(=3^{4}\right)$ tour plans, but it is necessary in the conjoint survey to limit these plans to a small number in order to easily make a comparison between them. The orthogonal arrangement produces an unbiased small number of plans. Then we have nine realistic tour plans (Table 1).

\section{PC Survey System for Investigation of Indonesian Sightseeing Resources}

\subsection{Features of the survey system}

The survey system was designed on a personal computer. The respondents were 
supposed to sit down in front of a personal computer and answer questions according to the instructions written on the monitor or played back in the headphones.

The advantage of this survey system is to be able to collect data of preferences under sufficient information, which are given using photos, and thereby equalize the conditions for all respondents under the same information environment. Moreover, we can get complete answers on all items because the system cannot go on to the next stage if a respondent does not answer the present question.

In order for respondents to grasp the holistic image of Indonesia, the system provided respondents with a lead-in explanation first, which explains the historical and cultural background of this country in detail using narrations and pictures. But in the Indonesian survey, this portion was omitted. The time required per respondent to finish answering was planned to be 15 to 20 minutes. All answers of respondents were recorded directly on files in a personal computer, and processed by a program that computes conjoint analysis utilities and AHP weights. The survey system was developed using a commercial authoring software and its commercial exclusive language (Macromedia Director and Lingo).

\subsection{Expressing preference by ranking tour plans}

To measure the value of the three components of the tour plans, we adopted the rankingtype conjoint model, which is one of the conjoint models of a decomposed type in the investigation. First, nine profiles (tour plans; see Table 1) are given on the screen, and a respondent places them in order of his/her preference. Then a whole and a partial utility are calculated from a sequence of tour plans arranged by his/her preference (see Section 2.1).

To rank nine profiles, these profiles are represented as cards in the system, and the respondent makes them move by moving the mouse to a specific place, where ranking was defined beforehand. The system is programmed to support respondents in their operations. That is, if cards are moved near a box, they fit onto it automatically. Two cards do not go into the same box, and so on. Naturally, only after all cards are put in order, the system goes on to the next stage.

\subsection{Expressing strength of preferences using pair-wise comparisons}

To clarify the configuration of tourists' attractions, the system asks respondents to compare three types of travel plans, and 12 photos related to sightseeing. These pictures are separated into three sets related to types of travel plan, each of which involves four pictures. Putting three types of travel plan on a higher rank and three sets of photos in a lower rank, a total of $21(=6 \times 3+3)$ pair-wise comparisons are made in AHP. In the AHP investigation, weights of each criterion are usually obtained by expressed ratios of integers on paired criteria. In this system, the ratios can be obtained using visual sensory scales, taking advantage of the characteristic of a personal computer. That is, the degree of movement of a button on a sliding scale ranging from 0 to 5 in each direction from the center $(0)$ is considered as a kind of ratio measure. A respondent can slide the button further to either side to indicate more attractive types or pictures of travel plans. 


\subsection{On-the-spot survey}

PC surveys have been conducted in Japan, United States, Netherlands, Singapore, and Indonesia from 2000 to 2002 (Table 2). The respondents targeted in the survey were undergraduate or graduate students in their twenties.

\section{Method of Measuring Value of Indonesian Sightseeing Resources}

\subsection{The monetary values of three types of travel plans}

As shown in Table 2, we carried out PC surveys two times in Japan. Here, we combine the data of these surveys because respondents of both are all first year students taking the same course and appearing to be homogeneous.

In equation (2.1.1), we suppose $I=9, J=4$ and matrix $\left(x_{j i}\right)$ is given by transposing Table 1 into it. Then coefficients $\beta_{1}, \beta_{2}$ and $\beta_{3}$ represent utility levels of travel per day (nature, traditional history, and agriculture, respectively). $\quad \beta_{4}$ represents utility level of traveling expenses per unit and can be considered to be negative. So, the ratios $-\beta_{1} / \beta_{4},-\beta_{2} / \beta_{4}$, $-\beta_{3} / \beta_{4}$ show the values in terms of money. That is, each of these values represents an additional traveling expense which offsets the extended travel plan for one more day.

\subsection{How to aggregate the value of three types of travel plans}

At first, we must restrict all expressed rankings to reliable ones. Lack of respondents' deliberation, difficulty in deciding on preferences, or a bad fit of the conjoint model for their preference structures would make their expressed rankings differ from the estimated rankings using the conjoint model. We define an effective ranking as one which can almost be replicated by parameters of the conjoint model. Further, there is another viewpoint that the respondent's expressed rankings are questionable. Table 3 shows the number of samples (expressed rankings) that produce non-negative utility on the four attributes in all surveys. The table shows that there is a considerable number of respondents whose answers seem to be strange. In fact, more than 15\% of expressed rankings lead to non-negative utilities on travel expenses. In the Indonesia survey, the number of these strange rankings amounts to around a half of all effective samples. These rankings seem to be caused by misunderstandings of respondents about the tour plans.

Although the four attributes of tour plans must be independent of each other in the

Table 2. Summary of survey characteristics

\begin{tabular}{|l|l|l|c|}
\hline \multirow{2}{*}{ Country } & \multicolumn{1}{|c|}{ Place } & \multicolumn{1}{c|}{ Date } & $\begin{array}{c}\text { Number of } \\
\text { respondents }\end{array}$ \\
\hline Japan & Tohoku University & $6^{\text {th }}$ Sept., 2000 & 197 \\
\cline { 3 - 4 } & & $7^{\text {th }}$ Sept., 2001 & 101 \\
\hline United States & Ohio State University & $4-5^{\text {th }}$ June, 2002 & 53 \\
\hline Netherlands & Wageningen University & $12-13^{\text {th }}$ June, 2002 & 46 \\
\hline Singapore & National University of Singapore & $21^{\text {st }}$ Feb., 2002 & 62 \\
\hline Indonesia & Gadjah Mada University & $25^{-26^{\text {th }}}$ Feb., 2002 & 148 \\
\hline
\end{tabular}


Table 3. Number of samples which give non-negative utility***

\begin{tabular}{|l|c|c|c|c|c|}
\hline Survey spot & Nature & $\begin{array}{c}\text { Traditional } \\
\text { History }\end{array}$ & Agriculture & $\begin{array}{c}\text { Traveling } \\
\text { expenses }\end{array}$ & $\begin{array}{c}\text { Effective } \\
\text { samples }\end{array}$ \\
\hline Japan & $195 / 190$ & $181 / 166$ & $81 / 86$ & $75 / 75$ & $281 / 283$ \\
\hline United States & $46 / 41$ & $30 / 40$ & $13 / 8$ & $8 / 9$ & $52 / 51$ \\
\hline Netherlands & $44 / 40$ & $37 / 31$ & $27 / 29$ & $3 / 7$ & $45 / 43$ \\
\hline Singapore & $38 / 49$ & $32 / 26$ & $12 / 19$ & $8 / 8$ & $61 / 62$ \\
\hline Indonesia & $95 / 96$ & $38 / 35$ & $87 / 80$ & $71 / 75$ & $146 / 144$ \\
\hline
\end{tabular}

* The left/right number in each cell corresponds to the first/second ranking.

** An expressed ranking is effective if the correlation coefficient (Kendall's $\tau$ ) between the ranking and the estimated one calculated by conjoint analysis is more than 0.5 .

conjoint model, some relationships exist between them, which respondents assume tacitly, and which give rise to these misunderstandings. For example, the same traveling expenses for a different number of days in a nature travel plan have an influence on the quality of the plan per day. We define reasonable rankings as ones that bring non-negative utility of traveling expenses.

For indices for evaluating sightseeing using expressed rankings on tour plans, two aggregation methods can be considered. One is to calculate utility levels or values on three types of travel plans by estimating parameters of the conjoint model on all effective samples. The other is to calculate them in every effective sample and to show characteristics of their distribution (e.g. mean, median, variance). Regarding utility levels, it would be meaningful to execute both methods to incorporate all the data efficiently. However, the respondents' monetary values, including questionable samples stated as above, would be inappropriate for aggregation because of unreliability in their rankings.

\subsection{Indices for evaluation of three travel plans}

Furthermore, we think the latter method stated above would be superior to the former one. The reason is related to a critical deficiency in a contingent value method (CVM), which is also an expressed preference method for environmental evaluation. In CVM, an object of evaluation is always assumed to have non-negative values, for we can't express ourselves negatively against the object under this method. This fact does not necessarily spoil CVM because prices of private goods in the market economy are decided in such a manner, where it doesn't matter whether there might be citizens who evaluate the goods negatively when the goods have no externality. But most environmental goods are always considered as public goods and do usually have some externality. Therefore, the assumption of the market economy in CVM leads to impartial values on environmental goods and the evaluation on CVM would not be fair to all citizens. Although the conjoint method is troublesome for respondents and difficult for researchers to make profiles, this method is one in which we can avoid the deficiency of CVM. In our case, the Indonesian survey had somewhat failed in setting traveling expenses for tour plans. To grasp such negative values on travel plans, we should calculate them in every effective sample and show characteristics 
of their distribution.

To sum up, the indices for the evaluation of travel plans are the following:

(1) utilities on four attributes per unit using a set of all effective rankings

(2) distribution of utility on three types of travel plans per day by each effective ranking

(3) monetary value per day of three types of travel plans by each effective and reasonable ranking.

\section{Configurations of Preferences on Indonesian Sightseeing}

\subsection{Structure of the AHP investigation}

The AHP model used here has two levels. The upper hierarchical level consists of three criteria: nature travel, traditional history travel, and agricultural area travel. Four pictures are given as the lower level criteria for each upper level (See Table 4). The survey system shows a pair of criteria on the same level, and respondents are asked to decide the amount of attractions to the preferred one compared with the other. The contents of 12 photos adopted are also shown in Table 4.

\subsection{Results of the AHP investigation}

Means of weights on criteria in AHP are shown in Figure 1. As regards to the upper criteria, respondents from all five countries except Japan were largely attracted to a nature travel plan. In contrast, most Japanese were attracted to a traditional history travel plan at more or less the same level as for the nature travel plan. Moreover, Indonesians were not very much interested in a traditional history travel plan ${ }^{2}$. After referring to respondents' impressions on our classification of travel plans, it turned out that some felt strange using this classification. That is, Indonesians might not have been able to identify with the concept of a farm village that had a long history and social stratification with present residents living harmoniously in their everyday life. In other words, they could not easily separate their history from agricultural daily life ${ }^{3}$.

Table 4. Photos given in the survey

\begin{tabular}{|l|l|l|l|l|}
\hline \multicolumn{1}{|c|}{ Upper criteria } & \multicolumn{4}{|c|}{ Lower criteria } \\
\hline Nature & Floating boats & A meandering river & Small islands & An active volcano \\
\hline Tradition & A folk dance & Old temples & A Royal Wagon & A statue of Buddha \\
\hline Agriculture & A farm village & Children in a field & A rice paddy & A vegetable market \\
\hline
\end{tabular}

2) Considering the large number of Islamic respondents in Indonesia, it is also possible that there was some resistance to a history filled with Buddhist and Hindu images. In their ranking, respondents first ranked categories according to the named categories of nature, tradition, and agriculture without photos, so it is possible that the image conjured up by these terms did not correspond to the reality of the pictures which represented a different cultural tradition based on Buddhism and Hinduism. A third possibility is that Indonesians view the past in the present and do not see these categories as distinctly different. In the case of AHP, we are using the term "criteria" to denote "Nature, Tradition and History, and Agriculture" whereas we use the term "attributes" for them when using the conjoint model. This is to conform with the terminology of these respective models.

3) Karatani says "Once Fuukei is formed, its origin is passed into oblivion. It looks to have existed as 

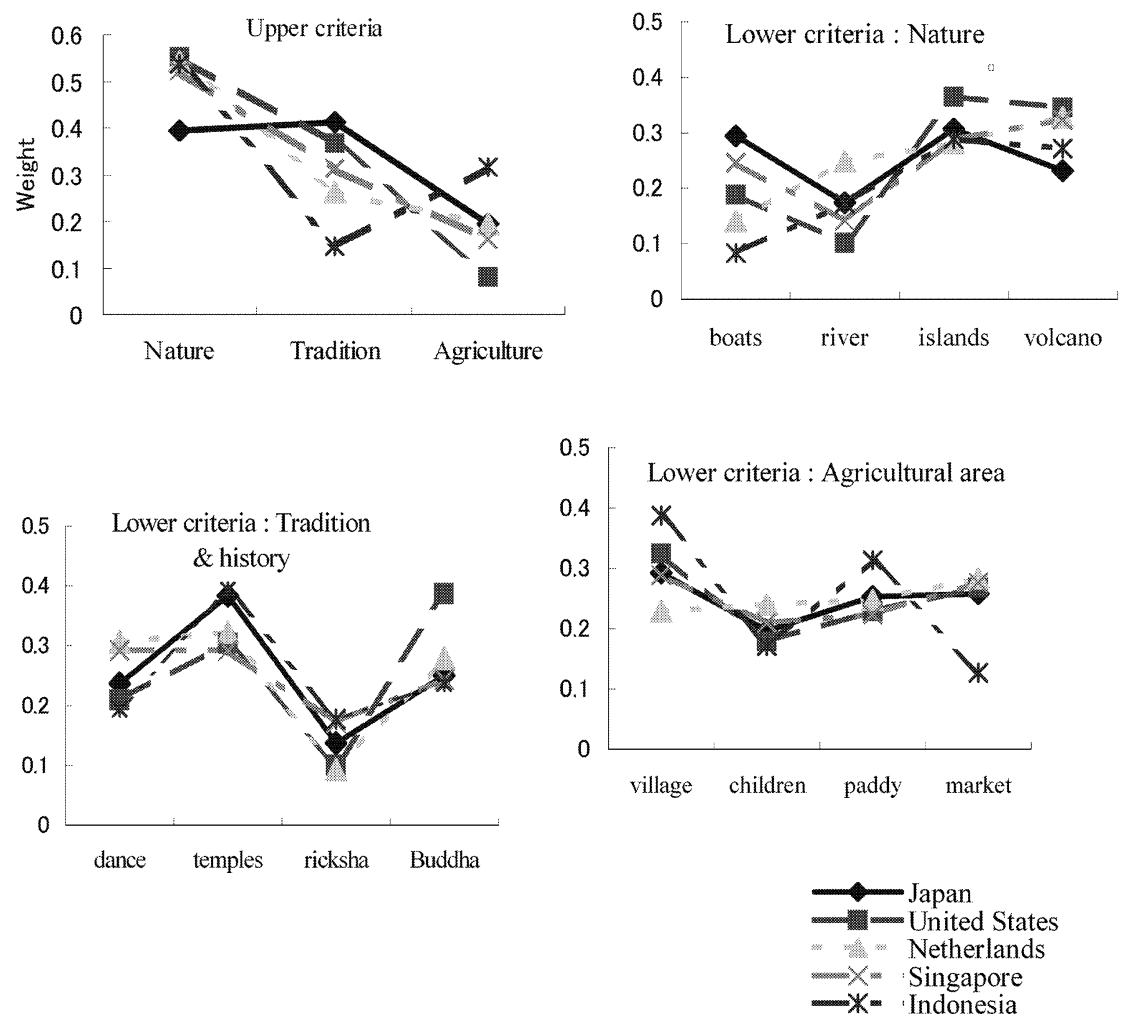

Figure 1. Mean of weights on criteria of AHP

Turning to the weight of the lower criteria (photograph), regarding nature travel, a small island and an active volcano attract respondents as a whole. To observe in detail, Japanese have a tendency to be attracted to boats floating ashore. Regarding traditional history travel, old temples attracted respondents most. A statue of Buddha attracted Americans. For agricultural travel, there were no large differences between the four photos except in the Indonesian case. Indonesians were attracted to the farm village and rice paddy.

\section{Values of Three Types of Travel by Conjoint Analysis}

\subsection{Estimated utilities on four attributes per unit $(\beta)$ using all effective samples}

Regarding the value of nature, tradition and history, and agricultural area travel, we summarize the parameters using all effective rankings in Table 5. Of course, parameters on travel expenses are calculated at the same time. These parameters can be utilities on each travel per a day or per money unit. We can easily see that the parameters on three travel plans could be referred to or explained by the weights on upper criteria on AHP.

It is meaningless to compare each parameter $\beta_{j}$ with the corresponding one in the other

an object from the beginning" [4]. However the object is rather derived in Fuukei. Fuukei is a Japanese word, which means life scenery or lifescape we coined in the other paper. According to Karatani's point of view, Indonesians consider "a traditional history" to be part of Fuukei, and have not identified it as an object yet. 

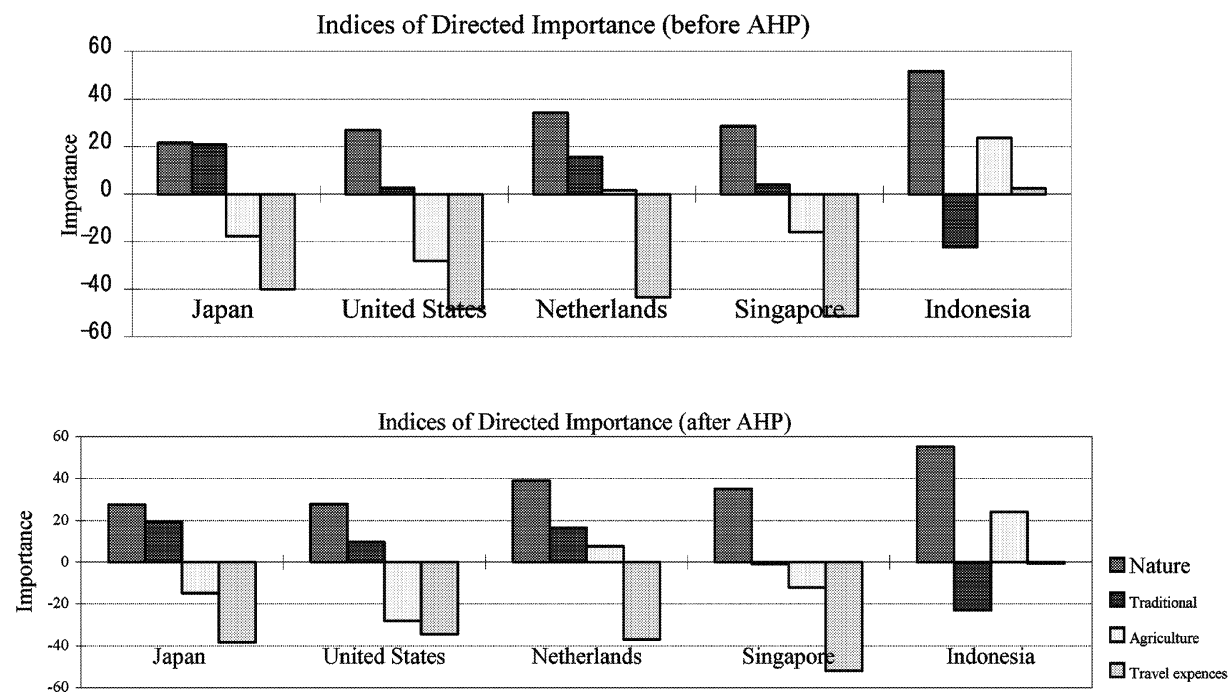

Figure 2. Indices of direct importance

survey, because it depends not only on the scale of its corresponding attributes but on the whole (Table 1). $\quad \beta_{j}$ can only be compared to each other within the same survey with the exception of travel expenses. Therefore, an index of the relative importance of each attribute is introduced in Figure 2, which shows the impact on a total utility when the level of the attribute in question changes and can thereby be compared throughout all the respective surveys. Importance indices of attributes are assigned value signs which represent the impact directions on total utilities.

As to influences on travel expenses, the relative importance became somewhat smaller after the AHP exercise except for Indonesians. In the survey of Indonesia, travel cost didn't work on respondents' preference on travel plans. Indonesian student's skill in English might be poor and perhaps they misunderstand the travel expenses in spite of supporting them to answer the system by graduate students, or Indonesian might be in confusion when tour plans are presented because contents of these plans are considered as a part of their daily life, not a travel.

According to Table 5, to see the particular influence of a conjoint analysis parameter (e. g. mean) by AHP investigation, a pair of parameters is shown, one of which was before AHP while the other was after AHP. Moreover, to see an effect from the AHP investigation, $t$ values of the mean difference test on non-independent samples (paired utilities or monetary values) are shown.

While nature travel had a high utility in all surveys, utility on agricultural area travel was negative except among the Dutch and Indonesians. The utility on tradition and history was very low except for the Japanese and the Dutch. This value was negative only in the Indonesian survey. As to the influence of AHP, natural and agricultural area travel became more favorable while traditional history became unfavorable. 
An Analysis of Non-exchangeable Values of Rural Environments

Table 5. Statistics on utility $(\beta)$ using all effective rankings***

\begin{tabular}{|c|c|c|c|c|c|c|}
\hline country travel & \multicolumn{2}{|c|}{ Nature } & \multicolumn{2}{|c|}{ Tradition and history } & \multicolumn{2}{|c|}{ Agriculture } \\
\hline Japan & Before AHP & After AHP & Before AHP & After AHP & Before AHP & After AHP \\
\hline mean & 0.288 & 0.362 & 0.279 & 0.250 & -0.238 & -0.191 \\
\hline median & 0.214 & 0.238 & 0.218 & 0.176 & -0.241 & -0.247 \\
\hline$\sqrt{ }$ variance & 0.527 & 0.509 & 0.622 & 0.653 & 0.697 & 0.703 \\
\hline positive portion & 70.8 & 70.7 & 64.4 & 60.4 & 33.7 & 35.4 \\
\hline$T$-value $(p), d f$ & \multicolumn{2}{|c|}{$t=2.15(.033), d f=273$} & \multicolumn{2}{|c|}{$t=-1.14(.254), d f=273$} & \multicolumn{2}{|c|}{$t=1.789(.075), d f=273$} \\
\hline \multicolumn{7}{|l|}{ United States } \\
\hline mean & 0.455 & 0.521 & 0.042 & 0.183 & -0.434 & -0.528 \\
\hline median & 0.405 & 0.383 & -0.042 & 0.120 & -0.444 & -0.541 \\
\hline$\sqrt{ }$ variance & 0.538 & 0.531 & 0.413 & 0.481 & 0.671 & 0.523 \\
\hline positive portion & 88.5 & 80.4 & 48.1 & 74.5 & 19.2 & 11.8 \\
\hline$T$-value $(p), d f$ & \multicolumn{2}{|c|}{$t=0.542(.590), d f=49$} & \multicolumn{2}{|c|}{$t=2.678(.010), d f=49$} & \multicolumn{2}{|c|}{$t=-1.883(.066), d f=49$} \\
\hline \multicolumn{7}{|l|}{ Netherlands } \\
\hline mean & 0.717 & 0.711 & 0.287 & 0.300 & 0.030 & 0.140 \\
\hline median & 0.680 & 0.708 & 0.319 & 0.218 & 0.156 & 0.100 \\
\hline$\sqrt{ }$ variance & 0.399 & 0.420 & 0.443 & 0.506 & 0.598 & 0.623 \\
\hline positive portion & 95.6 & 93.0 & 88.9 & 93.0 & 53.3 & 55.8 \\
\hline$T$-value $(p), d f$ & \multicolumn{2}{|c|}{$t=-0.171(.865), d f=42$} & \multicolumn{2}{|c|}{$t=0.132(.895), d f=42$} & \multicolumn{2}{|c|}{$t=1.537(.132), d f=42$} \\
\hline \multicolumn{7}{|l|}{ Singapore } \\
\hline mean & 0.467 & 0.535 & 0.066 & -0.015 & -0.262 & -0.185 \\
\hline median & 0.365 & 0.500 & 0.075 & -0.041 & -0.175 & -0.156 \\
\hline$\sqrt{ }$ variance & 0.634 & 0.580 & 0.493 & 0.479 & 0.467 & 0.521 \\
\hline positive portion & 75.0 & 79.0 & 55.7 & 48.4 & 26.2 & 37.1 \\
\hline$T$-value $(p), d f$ & \multicolumn{2}{|c|}{$t=1.287(.203), d f=60$} & \multicolumn{2}{|c|}{$t=-1.586(.118), d f=60$} & \multicolumn{2}{|c|}{$t=1.761(.083), d f=60$} \\
\hline \multicolumn{7}{|l|}{ Indonesia } \\
\hline mean & 0.886 & 0.927 & -0.384 & -0.407 & 0.406 & 0.428 \\
\hline median & 0.553 & 0.750 & -0.430 & -0.333 & 0.323 & 0.301 \\
\hline$\sqrt{ }$ variance & 1.207 & 1.231 & 1.072 & 1.098 & 1.293 & 1.268 \\
\hline positive portion & 69.9 & 74.3 & 32.2 & 31.9 & 63.7 & 59.0 \\
\hline$T$-value $(p), d f$ & \multicolumn{2}{|c|}{$t=0.394(.694), d f=141$} & \multicolumn{2}{|c|}{$t=-0.078(.938), d f=141$} & \multicolumn{2}{|c|}{$t=0.421(.674), d f=141$} \\
\hline
\end{tabular}

* Positive portion (\%) means the magnitude of respondents who place a positive utility on the travel plan in question.

** $T$-value is the test statistic for the paired mean difference ${ }^{4)}$ between the two rankings and shows the reliability of the effects of AHP. " $d f$ " shows a degree of freedom in the test.

4) It is known that the variance of sample median is $\pi / 2$ times as large as that of sample mean, supposing a random sample from a population with the normal distribution. In Table 6, we just show revised $t$-values for paired median differences in consideration with the difference of variance between the two sample statistics. 


\subsection{Monetary value of three travel plans}

Table 6 shows monetary values of travel plans using all effective and reasonable rankings. As to each travel plan, we can read characteristics of the distribution and refer to the influence of the AHP investigation. Although the value can be shown by various statistics according to the method of aggregation, we would like to mainly focus on the median of the distribution, for the other statistics (mean, mode, variance, etc) are vulnerable to some outlying values.

This is particularly the case for the monetary values which, defined through $\beta_{4}$, become especially sensitive as $\beta_{4}$ becomes small.

(1) Nature travel plan

Respondents in all surveys placed high values on a nature travel plan. Checking with the mean value, the distribution of the monetary value is largely positively skewed. In Japan, the United States and Singaporean surveys, the values got much higher after the AHP survey on the whole although in the American case the mean difference was not statistically significant. On the other hand, the values didn't get much higher in Netherlands survey.

(2) Tradition and history travel plan

The value of a tradition and history travel plan was very small for Americans and Singaporeans at first. But the AHP investigation had a positive influence on the value in only the American case while it was negative in the Singaporean case in contrast (just for

Table 6. Monetary value using all effective and reasonable rankings

\begin{tabular}{|c|c|c|c|c|c|c|}
\hline Country & \multicolumn{2}{|c|}{ Nature } & \multicolumn{2}{|c|}{ Tradition and History } & \multicolumn{2}{|c|}{ Agriculture } \\
\hline Japan & Before AHP & After AHP & Before AHP & After AHP & Before AHP & After AHP \\
\hline Mean ( $¥)$ & 9,040 & 13,760 & 8,720 & 6,580 & $-5,690$ & $-3,170$ \\
\hline Median ( $¥$ ) & 4,170 & 4,170 & 3,420 & 2,390 & $-2,080$ & $-2,340$ \\
\hline$T$-value $(p), d f$ & \multicolumn{2}{|c|}{$t=0.000(.500), d f=186$} & \multicolumn{2}{|c|}{$t=-0.076(.470), d f=186$} & \multicolumn{2}{|c|}{$t=-0.142(.445), d f=186$} \\
\hline \multicolumn{7}{|l|}{ United States } \\
\hline Mean $(\$)$ & 63.4 & 213.5 & 1.7 & 74.4 & -148.7 & -159.8 \\
\hline Median $(\$)$ & 41.7 & 53.8 & -7.3 & 25.0 & -31.2 & -64.1 \\
\hline$T$-value $(p), d f$ & \multicolumn{2}{|c|}{$t=0.058(.477), d f=36$} & \multicolumn{2}{|c|}{$t=0.154(.438), d f=36$} & \multicolumn{2}{|c|}{$t=-1.192(.127), d f=36$} \\
\hline \multicolumn{7}{|l|}{ Netherlands } \\
\hline Mean (Euro) & 193.3 & 197.9 & 94.8 & 125.1 & -17.8 & 53.6 \\
\hline Median (Euro) & 84.8 & 93.8 & 38.3 & 37.3 & 13.9 & 13.9 \\
\hline$T$-value $(p), d f$ & \multicolumn{2}{|c|}{$t=1.691(.0455), d f=35$} & \multicolumn{2}{|c|}{$t=-0.035(.486), d f=35$} & \multicolumn{2}{|c|}{$t=0.000(.500), d f=35$} \\
\hline \multicolumn{7}{|l|}{ Singapore } \\
\hline Mean $(\$)$ & 131.8 & 161.5 & 21.7 & 34.3 & -70.2 & -61.9 \\
\hline Median $(\$)$ & 35.3 & 54.5 & 7.2 & -3.4 & -12.2 & -12.4 \\
\hline$T$-value $(p), d f$ & \multicolumn{2}{|c|}{$t=0.947(.171), d f=49$} & \multicolumn{2}{|c|}{$t=-0.322(.375), d f=49$} & \multicolumn{2}{|c|}{$t=0.000(.500), d f=49$} \\
\hline
\end{tabular}


reference, we can see this difference in terms of utility, see, Table 5). The Japanese case also had a smaller value after the AHP, but the value is still considerably large. The figure of the distribution is also positively skewed.

(3) Agricultural area travel plan

The value of an agricultural area travel plan was negative except for the Dutch. But the Dutch appeared to have a larger value for the travel after the AHP, although Americans and Singaporeans still contributed to a lower value.

\subsection{Discussion}

Although almost all results on the value of the three travel plans were within our estimation, the influence of the AHP investigation on the value was larger than we expected. In particular, we note the variation of the value on agricultural area travel through the respondents' nationality and their vulnerability under AHP investigation. This fact approximated our expectations because we thought that we would not be able to consider an agricultural area as a sightseeing resource for traveling abroad. Of course, green tourism has been popular in many advanced countries but the tour is usually domestic.

One of the purposes of involving agricultural area travel is not on measuring the value as a whole but rather on grasping the number of respondents whose rankings lead to positive values. Referring to Table 3, we can see it as a considerably large part of all respondents (the values of more than one-third of the respondents in the Japanese case were positive, meaning that the figure of distribution is largely negatively skewed). Another purpose was to investigate the influence of AHP. Figure 2 shows that the value of agricultural travels does not necessarily decrease after the AHP investigation. Especially, in the Japan survey, the mean of the value increased largely.

\section{Evaluation in View of Respondents' Attitudinal Change}

\subsection{Model of attitudinal change on social judgments}

Although we have already shown the mean differences on three travel plans across the AHP investigation in Table 5, the differences cannot tell us the figures for attitudes of the respondents. Moreover, the paired mean difference test cannot give us information on the magnitude of attitudinal change. There might be a large attitudinal change even when the difference is small or the test is not significant.

In research in social psychology, Petty and Cacioppo proposed a model of consumers' attitudinal change on purchasing economic goods, called the Elaboration Likelihood Model (ELM) [8]. Roughly speaking, whenever consumers evaluate any economic goods, they would have magnitudes of elaboration likelihood which are determined by motivation for elaboration and cognitive capacity. When consumers are persuaded to buy or evaluate the goods, they will make their decisions or judgments according to the magnitude, that is, they will behave along substantive processing strategies regarding contents of persuasive messages when they have much, and will behave along heuristic processing strategies by peripheral cueing when they have little. These two types of strategies are derived from a multiprocess model for understanding mood effects proposed by Forgas [2] (see Figure 3).

In our five surveys, attitudes of respondents substantially differ from each other. That 


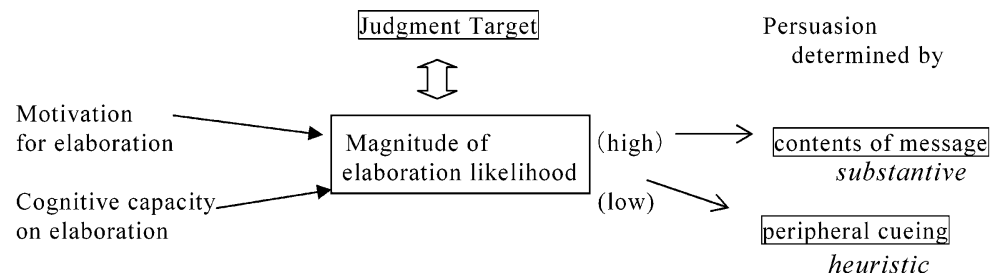

Figure 3. Elaboration of the likelihood model
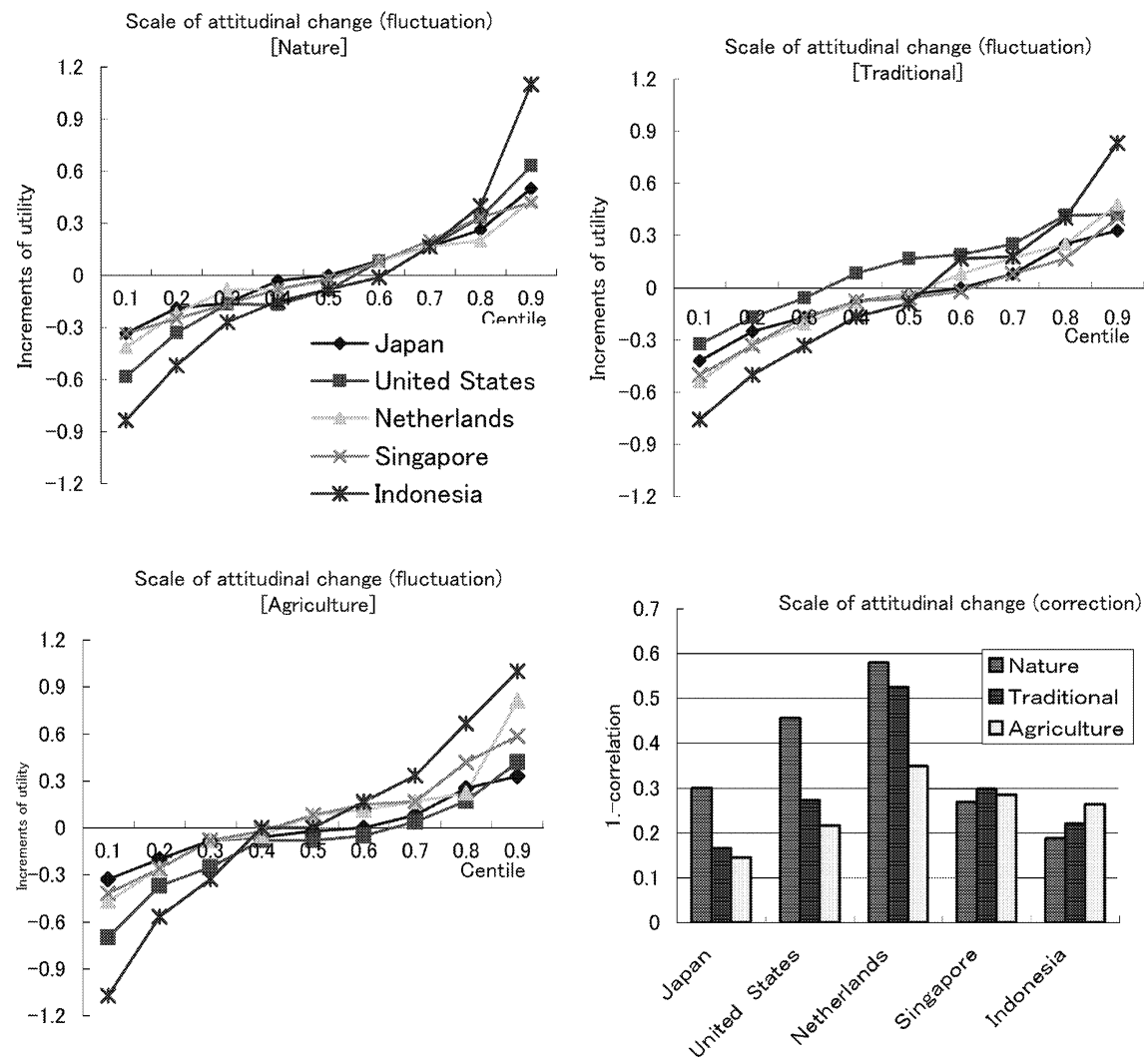

Figure 4. Attitudinal change concerning five surveys

is, Japanese, Singaporeans, and Indonesians seem to be familiar with Indonesian sightseeing, but Americans and the Dutch seem not to be (Figure 4).

Moreover, Indonesians seem to have a specific motivation or a personal involvement in the issue.

\subsection{Two measures of attitudinal change in this study and our results}

When we consider our AHP investigation as a kind of mapping the respondents' cognitive ability in evaluating Indonesian travel plans, American and Dutch respondents seem to be able to increase their cognition more strongly than the others. Therefore, their elaboration likelihood would be heightened after the AHP investigation. To see the scale of 
attitudinal change, we have two indicators : that is, a distribution of difference of utilities on travel plans across the AHP investigation, and non-correlation (1.-Peasons' coefficient) of those utilities. The former gives a figure of scale of individual attitudinal changes (fluctuation), which cannot be found in the difference of aggregated utilities as shown in Table 5 . The latter gives us individual direction changes of attitude, where the direction of ranking on tour plans plays a key role rather than the quantity of change. In other words, as the number of respondents who inversely correct their first rankings on tour plans increase, the correlation between utilities calculated by the first and second rankings becomes lower.

Figure 4 shows an attitudinal change in each of the five surveys. The figure is described by the cumulative distribution of increments of utility by AHP. First of all, we can see that attitudinal change in evaluating travel plans in the Indonesian survey is much larger than that in any of the other surveys. On the other hand, attitudes of Japanese and Singaporeans would not change as easily in the AHP investigation. But in the surveys of the three Asian countries, correlations between utilities by the pre and post AHP rankings were relatively large. This means that Indonesians might have strengthened the attitude themselves rather than the direction of the attitudes for travel plans. In contrast, the Dutch tended to change directions of their attitudes after the AHP investigation while the Americans did so in the natural travel plan.

\subsection{Meanings of attitudinal change of utilities on three components of tour plans}

In this section, we attempt to explain the results of attitudinal change after the AHP investigation using ELM. With regard to the Indonesia travel, Indonesians must have had cognitive capacities on elaboration even before the AHP because they would already be familiar with Indonesian environments. Moreover, the AHP investigation would function as strengthening their motivation for elaboration, for Indonesians would become conscious of personal involvements through pair-wise comparisons between photographs. It follows from these considerations that Indonesian respondents have a relatively large magnitude of elaboration likelihood from the first decision and they would develop an even larger magnitude in the second. In view of ELM, Indonesians would adopt substantive processing strategies throughout the survey and the AHP made them confirm their preference of tour plans. We think this inference could be supported by the fact that Indonesians expressed their attitudes more clearly in the second judgmental situation.

On the other hand, Americans and the Dutch had little information beyond that given in the PC survey because they were not familiar with Indonesia. Therefore, the AHP investigation functioned as heightening cognitive capacity on elaboration. It follows that they had a smaller magnitude for elaboration at first and developed a relatively large magnitude in the second decision. That is, they would adopt heuristic processing strategies by peripheral cueing in the first judgmental situation and change to substantive processing strategies in the second. This inference might be supported if we suppose that heuristic processing strategies are apt to bring about random guessing on the first judgmental situation. In other words, changing directions of attitudes after the AHP in the American and the Dutch cases can be considered as a phenomenon caused by this randomness.

It might be important for us to pay attention to the difference between the Americans 
and the Dutch. American respondents changed their attitudes only on the nature travel plan, while on the other hand, the Dutch respondents changed their attitudes on all their travel plans. On the face of this fact, we cannot help recalling the difference of history and agriculture between these countries. Here, we shall not comment on this for lack of space. We have already referred to something related to this point in another survey [5], where we have confirmed that accessibility to agriculture has a relation to the vulnerability of evaluation attitudes to the AHP investigation of agricultural landscape.

\section{Conclusion}

We considered the process of valuation as a repeated decision (before, and after the AHP investigation). The motivation of this Indonesian sightseeing survey is founded on our prior study [6], that is, we might find a relationship between vulnerability of respondents' decisions and their access to a specific agricultural landscape. After this study, we started doubting whether CVM (as the method for evaluating agricultural landscapes) would be relevant to our objectives or not, and thought we might find a similar problematic relationship when we evaluated foreign agricultural landscapes in the framework of micro-economics. As to the CVM criticism, we have described this in section 4.3. In order to clarify the latter problem which is not addressed by micro-economics, we constructed a report of traveling to Indonesia including agricultural areas.

On the whole, Japanese and Singaporeans had common tendencies of evaluating travel plans except for traditional and history travel plans. Americans gave the lowest value for agricultural area travel, which became even lower after AHP. In contrast, Japanese and Singaporeans assigned a higher value to it. Our interpretation of this is that although they seem not to be able to have images of agricultural areas or understand the meaning of farm life, Japanese and Singaporeans became conscious of the value after the AHP investigation while Americans did not.

The Dutch and Indonesians were more vulnerable when evaluating agricultural area travel, Indonesians having placed high values on it. This seems to depend partly on the fact that most Dutch and Indonesians have more accessibility to agricultural areas, farm life, or playing on a farm village than do Americans.

Considering the fact that we found a number of phenomena which were not accounted for through CVM, it is necessary to widen the dimensions of our analytical evaluation. Although there seem to be many ways to interpret our results, it shows that we should discuss the future of agriculture with a model which is not only based on the framework of market economics, but within a context that includes the views of ethics and environmental education.

There are at least two conditions of the survey to be considered in future research. First, we restricted respondents of the survey to young university students. The reason is that we wanted to use a PC system to make the information circumstances of the survey homogeneous. Fortunately, students could easily operate personal computers. Moreover, because almost all respondents except Indonesians were supposed not to have been to Indonesia, we could give them impartial visual information. Needless to say, we have to keep in mind that the survey was intended for people with little foreign tour experience. 
Second, the PC system provided limited information for the respective tour plans. Naturally enough, the results would change when we gave more information on the plans. Therefore, the difference between the preferences for the three types of tour plans within the same country was not relevant. The main objective of our study was a comparison between the five countries, especially on the difference of attitudinal changes.

\section{References}

[1] Callicott, J.B., In Defense of Land Ethic. Albany, New York: SUNY Press, 1989.

[2] Forgas, J.P., "Affect in social judgments and decisions: A multiprocess model," In Zanna, M.P. (ed) Advances in experimental social psychology, vol. 25 Academic Press, 1992, pp. 227-276.

[ 3 ] Heller, T.C., "The importance of normative decision-making: the limitations of egal economics as a basis for a liberal jurisprudence-as illustrated by the regulation of vacation home development," Wisconsin Law Review, 1976, p. 405.

[4] Karatani, K., The origin of Japanese modern literature (Nihon-Kindai-bungaku no Kigen), Kodansha, 1980 [In Japanese].

[5 ] Kitani, S., Hasebe, T., and Nomura, N., "Effects on conscious and willingness to defend rural scenery through the process of rural image formation," Journal of Farm Management Economics, No. 32, 2000, pp. 13-22 [ In Japanese].

[6 ] Kitani, S., Hasebe, T., Nomura, N., and Moore, R., "Effects of Image Formation of Rural Lifescape on Conscious and Willingness to Protect Rural Farming Villages," The Japanese Journal of Rural Economics, Vol. 7, 2005, pp. 101-115.

[ 7 ] Mepham, B., "Agricultural Ethics," in R. Chadwick, ed., Encyclopedia of Applied Ethics 1, Academic Press, 1998, pp. 95-110.

[8] Petty, R.E. and Cacioppo, J.T., Communication and persuasion: central and peripheral routes to attitude change, Springer-Verlag, 1986.

[9] Sagoff, M., The Economy of the Earth, Cambridge University Press. Cambridge, 1988.

[10] Shrader-Frechette, K.S., "Agricultural Ethics," in Becker, L.C. \& Becker, C.B eds., Encyclopedia of Ethics 1, Garland Publishing Inc., 1992, pp. 30-33.

[11] Thompson, P.B., “Agricultural Ethics," Iowa State University Press, IA, 1976. 